\title{
Vibration Energy Harvest for Low Frequency using Double- piezoelectric Cantilever Beam
}

\author{
Chuttipong Tuma* and Danai Phaoharuhansa \\ Department of Mechanical Engineering, Faculty of Engineering, King Mongkut's University of Technology Thonburi, Bangkok, \\ Thailand
}

\begin{abstract}
This study introduces design methods of natural frequency for double-piezoelectric cantilever beams in order to absorb electricity from mechanical vibration. The natural frequencies of double cantilever beams are designed by quadratic equation such as 6.45 and $18.14 \mathrm{~Hz}$. On the other hands, FEA is used to recheck the result. FEA simulation presents the natural frequencies such as 4.4614, 8.4793, 13.8020 and $25.1050 \mathrm{~Hz}$. It works in low frequency and large bandwidth. The experimental results show the peak electric power at 5 and $22 \mathrm{~Hz}$. The error may occur by stiffness of piezoelectric and effective of mounting position.
\end{abstract}

\section{Introduction}

Piezoelectric is used to convert vibration energy to electricity. It is usually attached on mechanism, which absorb some force or pressure. Stress and strain with occur in the structure. Then, piezoelectric generate electricity relative to amount stress and strain. So that it obtains good performance of high frequency.

The most piezoelectric cantilever beam is designed only one frequency, it has a natural frequency related to ambient vibration sources [1]. The single piezoelectric cantilever beam gives narrow bandwidth. Performance of single cantilever beam decreases when ambient vibration sources changed frequency.

Several papers [2-5] present the multiple cantilever beam arrays. It increases bandwidth and electric power for scavenge vibration energy ambient. So, it advantages more than single cantilever beam. The most multiple cantilever beams were designed natural frequency between 22 to $245 \mathrm{~Hz}$. Multiple cantilever beams stacked to increase the bandwidth of natural frequencies. It is well known as piezoelectric cantilever beam arrays. The bandwidth of piezoelectric cantilever beam arrays is tuning mass or dimension beam.

Frequency of double-piezoelectric cantilever beams can tune by changing tip mass or stiffness. Therefore, this paper deals quadratic equation and finite element method (FEM) for tuning natural frequency of the double-piezoelectric cantilever beams. FEA is descriptive detail of geometry, is a powerful for mechanical engineering problems. The solutions of FEA are verified condition of the problem [6-7].

This paper aims to design the double cantilever beams to harvest the energy, frequency of which should lower than $22 \mathrm{~Hz}$. The low frequency will be suitable for ambient energy.

\section{Piezoelectric energy harvest}

Piezoelectric material can generate electric when it receives some force. Stress and strain occur in material as shows in the Fig. 1. It calls direct piezoelectric phenomenal.

The relationship of stress, strain and electric field of piezoelectric [8], it is given as

$$
T_{p}=E_{p} S_{p}-e_{p} E_{p}
$$

where, $T_{p}$ and $S_{p}$ are stress and strain in piezoelectric plate. $E_{p}$ is young's modulus of piezoelectric, $e_{p}$ is piezoelectric coefficient and $E_{p}$ is electric field of piezoelectric.

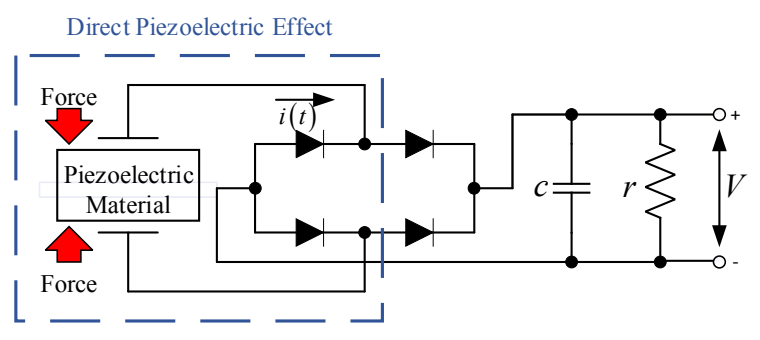

Fig. 1. Phenomenal direct piezoelectric.

\section{Double mass spring system}

The double-piezoelectric cantilever beams as shown in Fig. 2, they consist of two springs and two tip masses. The clamped area is attached to moving base. The base excitation has been moving sinusoidal. The mathematical model of double-piezoelectric cantilever beams under base excitation is given as

\footnotetext{
* Corresponding author: chuttipong.tuma@gmail.com
} 


$$
\begin{gathered}
y(t)=y_{0} \sin (\omega t) \\
m \ddot{x}+k x=U
\end{gathered}
$$

where, $m=\left[\begin{array}{cc}m_{1} & 0 \\ 0 & m_{2}\end{array}\right], x=\left[\begin{array}{l}x_{1} \\ x_{2}\end{array}\right], \ddot{x}=\left[\begin{array}{c}\ddot{x}_{1} \\ \ddot{x}_{2}\end{array}\right]$, $U=\left[\begin{array}{c}k_{1} y(t) \\ 0\end{array}\right]$ and $k=\left[\begin{array}{cc}k_{1}+k_{2} & -k_{2} \\ -k_{2} & k_{2}\end{array}\right], m_{1}$ is first tip mass and $m_{2}$ is second tip mass, $k_{1}$ is first spring stiffness constant and the $k_{2}$ is second spring stiffness constant, $y_{0}$ and $\omega$ are the amplitude of base excitation and frequency of base excitation, respectively. $\ddot{x}_{1}$ and $\ddot{x}_{2}$ are the acceleration of $m_{1}$ and $m_{2}$, respectively. $x_{1}$ and $x_{2}$ are the displacement of $m_{1}$ and $m_{2}$, respectively.

The natural frequency of the two-degree freedom system can find from underdamped vibration equation, it is written as

$$
m \ddot{x}+k x=0
$$

Two possible natural frequencies obtained from quadratic equation [9] as

$$
\operatorname{det}\left(-\omega^{2} \mathrm{M}+\mathrm{K}\right)=0
$$

In this paper, double cantilever beams are designed two natural frequency, such as 6.45 and $18.41 \mathrm{~Hz}$.

\section{Mechanical of single cantilever beam}

Fig. 3 shows the single cantilever beam with the tip mass system. The cantilever beam has behaviour as spring. The spring stiffness is calculated by deflection of cantilever beam [10], it is given as

$$
\delta_{\max }=\frac{m g l^{3}}{3 E I}
$$

where, $m$ is the mass of tip mass, $E$ is the young's modulus of material, $l$ is length of beam and $I$ is the moment of inertia of cantilever beam. as

The spring stiffness of cantilever beam is expressed

$$
k=\frac{F}{x}=\frac{m g}{\delta_{\max }}=\frac{3 E I}{l^{3}}
$$

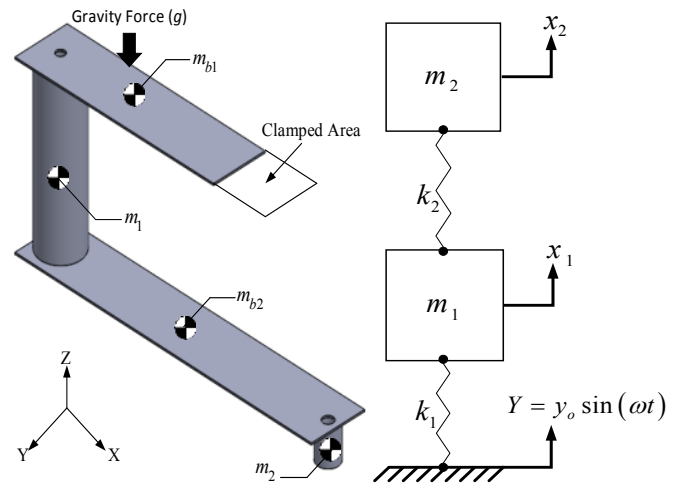

Fig. 2. Geometric of double mass spring.

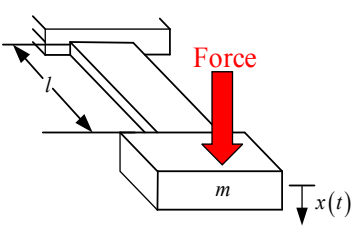

(a) Cantilever beam attach mass

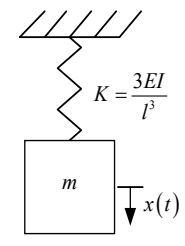

(b) Cantilever beam mechanical model 1 DOF

Fig. 3. Single cantilever beam with tip mass.

\section{Finite element analysis of double- piezoelectric cantilever beam design}

Finite element analysis (FEA) can derive the mathematical model of engineering problem.

The structure of double cantilever beams was calculated maximum stress because the double cantilever beams are received by gravity force as shown in Fig. 2. When a cantilever beam has a stress nearby yield strength of mechanical material properties which provide higher electrical power.

From the shape function of beam element, beam element stiffness matrix can be derived from Galerkin's method [11]. Stiffness of the beam is defined that

$$
K=\frac{E I}{L^{3}}\left[\begin{array}{cccc}
12 & 6 L & -12 & 6 L \\
6 L & 4 L^{2} & -6 L & 2 L^{2} \\
-12 & -6 L & 12 & -6 L \\
6 L & 2 L^{2} & -6 L & 4 L^{2}
\end{array}\right]
$$

Lumped-mass element matrix in FEA is defined that

$$
M=\frac{\rho A L}{420}\left[\begin{array}{cccc}
156 & 22 L & 54 & -13 L \\
22 L & 4 L^{2} & 13 L & -13 L^{2} \\
54 & 13 L & 156 & -22 L \\
-13 L & -13 L^{2} & -22 L & 4 L^{2}
\end{array}\right]
$$

\subsection{Static Structure analysis of double cantilever beams}

The stress on the structure is calculated by static structural analysis. In this paper, cantilever beams are created by aluminum material. Spring stiffness can calculate from Eq. (7) and natural frequency of double 
cantilever beams can calculate from Eq. (5). The proprieties of top and bottom cantilever beams shown as Table 1 and 2, respectively. Maximum stress is occurring on top cantilever beam because it received all masses. The comparison between spring stiffness with stress, which relate to increasing tip mass on cantilever beams is shown in Fig. 4. The indicates comparison between the thickness of a cantilever beam with stress is shown in Fig. 5. The cantilever thickness $1 \mathrm{~mm}$ beam has a stress nearby yield strength of aluminum properties.

Table 1. Proprieties of top cantilever beam

\begin{tabular}{|c|c|c|c|c|}
\hline $\begin{array}{c}\text { Thickness } \\
(\mathrm{mm})\end{array}$ & $\begin{array}{c}\text { Stiffness of } \\
\text { Top } \\
\text { cantilever } \\
\text { beam }\left(\mathrm{N} / \mathrm{m}^{2}\right)\end{array}$ & $\begin{array}{l}\text { Width } \\
(\mathrm{mm})\end{array}$ & $\begin{array}{c}\text { Length of } \\
\text { Top } \\
\text { cantilever } \\
\text { Beam }(\mathrm{mm}) \\
\end{array}$ & $\begin{array}{c}\text { Tip } \\
\text { mass } \\
(\mathrm{kg})\end{array}$ \\
\hline 0.5 & 65.625 & \multirow{5}{*}{30} & \multirow{5}{*}{100} & 0.0038 \\
\hline 1.0 & 525.0 & & & 0.305 \\
\hline 1.5 & 1771.87 & & & 1.03 \\
\hline 2.0 & 4200.0 & & & 2.4402 \\
\hline 2.5 & 8203.13 & & & 4.766 \\
\hline
\end{tabular}

Table 2. Proprieties of bottom cantilever beam

\begin{tabular}{|c|c|c|c|c|}
\hline $\begin{array}{c}\text { Thickness } \\
(\mathrm{mm})\end{array}$ & $\begin{array}{c}\text { Stiffness of } \\
\text { Bottom } \\
\text { cantilever } \\
\text { beam } \\
\end{array}$ & $\begin{array}{c}\text { Width } \\
\left(\mathrm{N} / \mathrm{m}^{2}\right)\end{array}$ & $\begin{array}{c}\text { Length of } \\
\text { bottom } \\
\text { cantilever } \\
\text { Beam }(\mathrm{mm})\end{array}$ & $\begin{array}{c}\text { Tip mass } \\
(\mathrm{kg})\end{array}$ \\
\hline 0.5 & 19.44 & & & 0.0015 \\
\hline 1.0 & 155.6 & \multirow{2}{*}{30} & \multirow{2}{*}{150} & 0.0122 \\
\hline 1.5 & 525 & & 0.041 \\
\hline 2.0 & 1244.4 & & & 0.0972 \\
\hline 2.5 & 2430.56 & & & 0.1898 \\
\hline
\end{tabular}

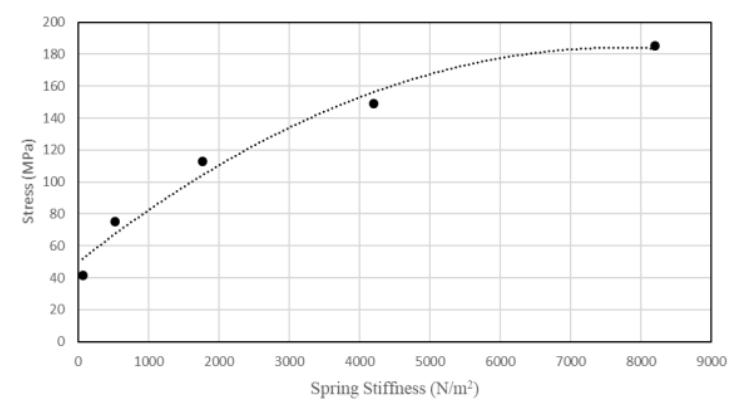

Fig. 4. Spring stiffness versus stress.

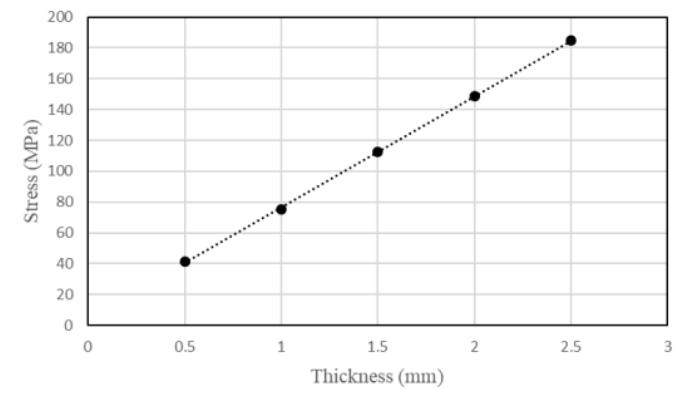

Fig. 5. Thickness stiffness versus stress.

\subsection{Modal analysis of double cantilever beams}

According to the double spring mass system, it can use modal analysis to solve the dynamics model. The modal analysis can derive the natural frequency and mode shape of structure. The boundary condition is shown in Fig. 2 and the simulation is neglected gravity force. Fig. 6 presents the modal analysis result and it consists of 4 modes shapes such as bending and swaying of the both beams.

The first mode shape is that the bending mode of the top plate cantilever beam and the natural frequency equals $4.4614 \mathrm{~Hz}$ as shown in Fig. 6(a). The second mode is that the bending mode of the bottom plate cantilever beam and the natural frequency equals 13.802 $\mathrm{Hz}$ as shown in Fig. 6(b). The third mode shape is that bending mode of both plate cantilever beam and natural frequency equals $25.105 \mathrm{~Hz}$ as shown in Fig. 6(c). The fourth mode shape is that the swaying mode of the bottom plate cantilever beam and the natural frequency equals $8.4793 \mathrm{~Hz}$ as shown in Fig. 6(d).

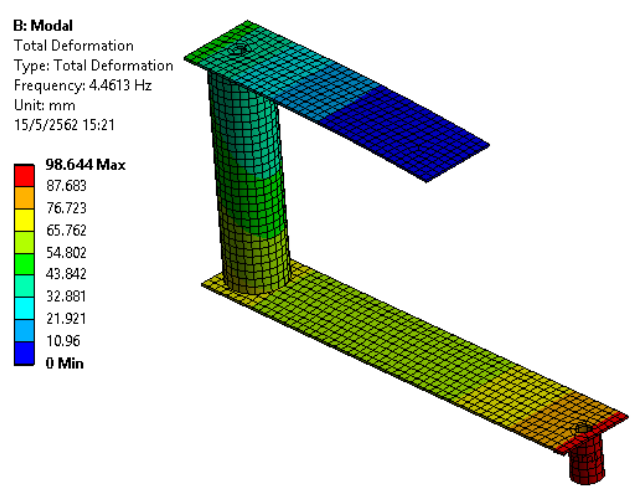

(a) first mode bending

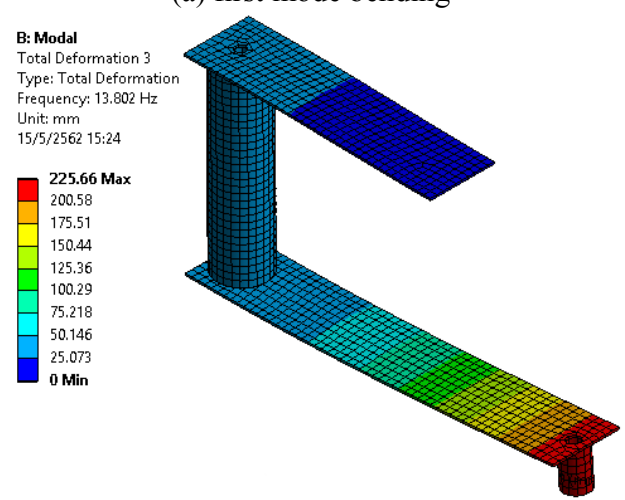

(b) second mode bending

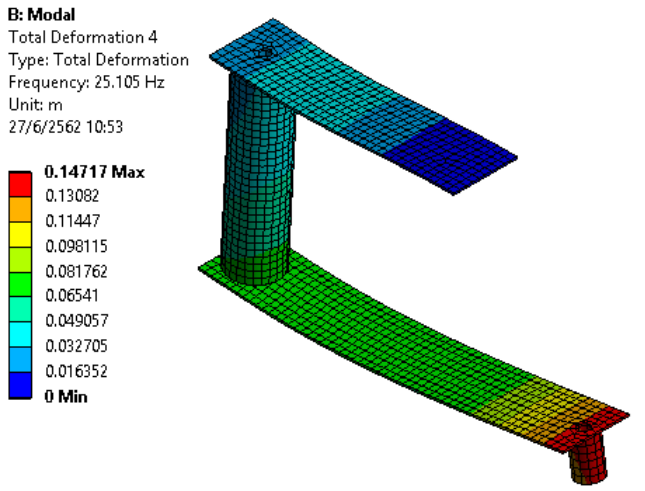

(c) third mode bending 


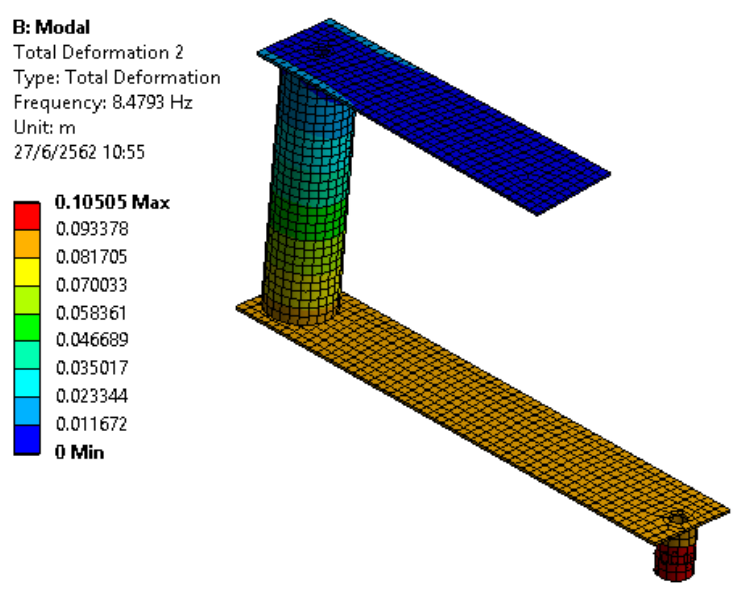

(d) fourth mode swaying

Fig. 6. Natural frequency and mode shape of double cantilever beam arrays system (a) bending mode of top plate cantilever beam (b) bending mode of bottom plate cantilever beam (c) bending mode of both plate cantilever beam (d) swaying mode of bottom plate cantilever beam.

\section{Experiment and result}

To experiment the double-piezoelectric cantilever beams in Fig. 2, base excitation experiment kit has developed as shown in Fig. 7. It consists of roller guide, moving base, stepping motor and encoder. The beam is clamped at clamp area with a moving base as shown in Fig. 2 and the moving base has been moved on the roller guide by stepping motors. The frequency of moving base is between $0.15-30 \mathrm{~Hz}$.

PPA-1001 is a piezoelectric plate that it used to harvest energy in the experiment, and the properties are exhibited in Table 3 maximum power obtain at $70 \mathrm{k} \Omega$. The power of double-piezoelectric cantilever beams is defined as

$$
P_{V}=\frac{V^{2}}{r}
$$

where, $V$ is the voltage across the electronic load resistance and $r$ is the electronic load resistance.

\begin{tabular}{|c|c|c|}
\hline Frequency $(\mathrm{Hz})$ & 22 & 22 \\
\hline Maximum Power (mW) & 1.4 & 4.4 \\
\hline Maximum Voltage (V) & 9 & 17.3 \\
\hline Maximum Current (mA) & 0.1 & 0.3 \\
\hline
\end{tabular}

Table 3. Properties of PPA-1001 piezoelectric plate

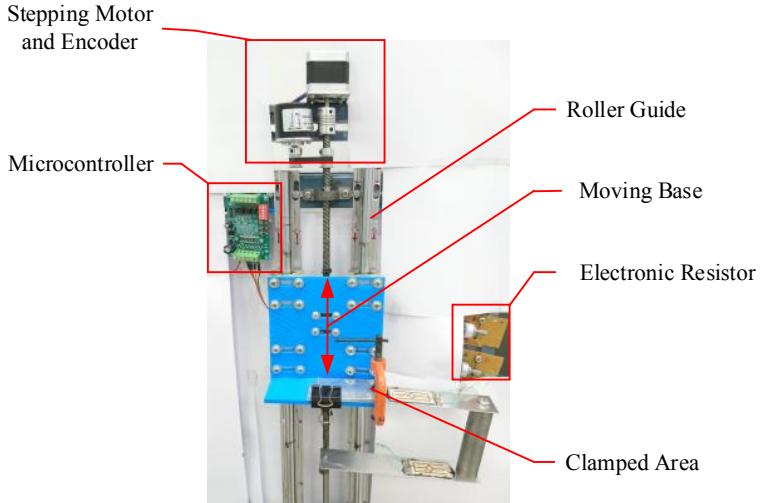

Fig. 7. Base excitation prototype.

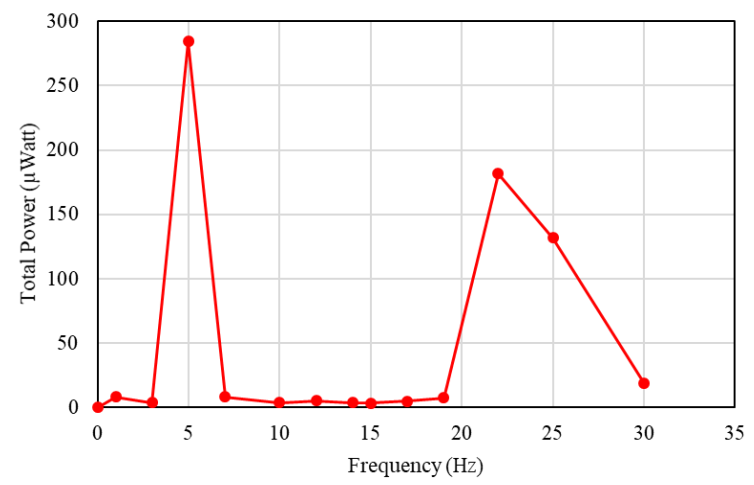

Fig. 8. Total power output versus frequency at $1-30 \mathrm{~Hz}$.

Power of double-piezoelectric cantilever beams at $0.15-0.2 \mathrm{~Hz}$ is an increase in a linear trend-line equation. Power of double-piezoelectric cantilever beams are equal, $0.2995 \mu \mathrm{W}$ at $0.15 \mathrm{~Hz}, 0.4159 \mu \mathrm{W}$ at $0.175 \mathrm{~Hz}$ and $0.2 \mu \mathrm{W}$ at $0.2 \mathrm{~Hz}$.

Fig. 8 exhibits compare between total power of double-piezoelectric cantilever beams in the frequency range $1-30 \mathrm{~Hz}$, the first peak total power is $284.4 \mu \mathrm{Watt}$ at $5 \mathrm{~Hz}$, and the second peak total power is $181.78 \mu \mathrm{Watt}$ at $22 \mathrm{~Hz}$.

\section{Conclusion}

Double-piezoelectric cantilever beams in this study are designed for low frequency. The natural frequencies of beams are designed at 6.45 and $18.41 \mathrm{~Hz}$, respectively. FEA simulation presents the natural frequencies such as $4.4614,8.4793,13.8020$ and $25.1050 \mathrm{~Hz}$, respectively. The error of FEA simulation occurs by calculating mass of cantilever beams. The peak power of experiment is $284.4 \mu \mathrm{Watt}$ at $5 \mathrm{~Hz}$ and $181.78 \mu \mathrm{Watt}$ at $22 \mathrm{~Hz}$, respectively. The frequencies at peak power are bending mode of top plate and bending mode of both plates. Therefore, the natural frequencies of the experiment have a slight error from mathematics model and FEA simulation. The error may occur by the clamp position and the stiffness of piezoelectric plate. 


\section{References}

1. Eli S. Leland, Jessy Baker, Eric Carleton, Elizabeth Reilly, Elaine Lai, Brian Otis, Jan M. Rabaey, V. Sundarajan and Pual K. Wright, Improving power output for vibration-Based energy scavengers, Energy harvesting \& conservation, IEEE Pervasive Computing 4, pp.28-36 (2005)

2. In-Ho Kim, Hyung-jo Jung, Bo Mi Lee and Seonjun Jang, Broadband energy harvesting using two degree-of-freedom vibration body, Applied Physics Letter 98, pp.1-3 (2011)

3. Yu-Yin Chen and Dejan Vasic, Energy harvesting of two cantilever beams structure: Inter facing circuit discussion, SPIE Smart Structures and Nondestructive Evaluation (2015)

4. Eduard Dechant, Feodor Dedulov, Leonid Y. Fetisov and Mikhail Shamonin, Bandwidth widening of piezoelectric cantilever beam arrays by mass-tip tuning for low-frequency vibration energy harvesting, Applied Science 7, 12(2017)

5. S. C. Lin, B.S. Lee, W.J. Wu and C.K. Lee, Multicantilever piezoelectric MEMS generator in energy harvesting, IEEE International Ultrasonics Symposium (2009)

6. C. Birleanu, S. Talu, Machine elements. Designing and computer assisted graphical representations, Cluj-Napoca, Romania, Victor Melenti Publishing house, (2001). ISBM 973-99539-6-4.

7. T. Nitulescu, S. Talu, Applications of descriptive geometry and computer aided design in engineering graphics, Cluj-Napoca, Romania, Risoprint Publishing house, (2001). ISBN 973-656-102-X.

8. Renato Calio, Udaya Bhaskar Rongala, Domenico Camboni, Mario Milazzo, Cesare Stefanini, Gianluca de Petris and Calogero Maria Oddo, Piezoelectric Energy Harvesting Solution, Sensors 14, pp.4755-4790 (2014). ISSN 1424-8220.

9. S. Graham Kell, Fundamentals of Mechanical Vibrations, McGraw-Hill Companies 2, pp.296 (2000)

10. Singiresu S. Rao, Mechanical Vibrations, Prentice Hall 5, pp.28 (2011)

11. Xiaolin Chen and Yijun Liu, Finite Element Modeling and Simulation with ANSYS Workbench, CRC Press 1, pp. 63-65, 228-230 (2015) 